\title{
Validation of the Prediction of ČEZ Stock Prices
}

\author{
Petr Šuleřํㅜ, Jakub Horák², Tomáš Krulický² \\ 1Institute of Technology and Business in České \\ Budějovice, School of Expertness and Valuation, Czech Republic \\ ${ }^{2}$ Department of Economics, Faculty of Operation and Economics of Transport and \\ Communications, University of Žilina, Slovakia
}

\begin{abstract}
Stock price developments are a nonlinear and dynamic process. Stock price prediction is one of the most important issues in stock markets. The aim of this paper iis paper aims to verify the prediction of the stock prices of ČEZ, a. s. on the Prague Stock Exchange. The main goal is decomposed into two sub-goals: evaluate the accuracy of the prediction using neural networks on stock price data that followed the time series used to calculate neural networks in the contribution of Vrbka and Rowland (2017) and generate new neural structures. 1,442 records of price data on stock are used. Multilayer Perceptron Neural Networks and Neural Networks of Basic Radial Functions are generated. The original neural networks are inappropriate to predict the evolution of ČEZ stock prices. Optically, two new neural structures can be used in practice. The practical use of new networks is not tested on data that did not enter the calculation. New networks show lower performance in all three sets of data.
\end{abstract}

Keywords: Artificial neural networks, prediction, stock prices, time series, Czech Republic

\section{Introduction}

Stock prices evolve in a non-linear way and therefore stock price prediction is one of the most important issues in stock markets. In viewBecause of this view Etemadi et al. (2015) insist that earnings per share are seen by managers, investors and financial analysts as 
one of the most important financial indicators. A number of Several methods and technologies are devoted to predicting these prices (Groda and Vrbka, 2017). Basic characteristics of stock prices are sensitivity, stationarity, asymmetry and volatility. Investors, of course, want to fully predict the movement of stock prices, it is a stochastic process (Vrbka and Rowland, 2017). Stock price developments are a nonlinear and dynamic process, and there are a number of some macroeconomic, industrial and corporate factors that can affect stock prices. These include, for example, global stock price indices, total economic activity, exchange rate, interest rate, and more (Wang and Nguyen, 2015). According to Sheelapriya and Murugesan (2016), it is essential to provide a reliable method that overcomes the complex forecast and allows to capture the development of stock prices in the financial market. However, successful price prediction can be very useful. It is no surprise, that the most accurate prediction attracts analysts from around the world (Klieštik et al., 2018).

\section{Methods and Data}

As already mentioned above, there are currently a number of applications and new technologies for stock price prediction such as neural networks, the ARIMA method, etc. Groda and Vrbka (2017) used the ARIMA (Box-Jenkins) method to analyze and predict stock prices. ARIMA, the AutoRegressive Integrated Moving Average model, is one of the most widely used models in time series prediction. At present, the ARIMA model is often used for its unique predictive ability as well as for predicting stock price developments (Pai and Lin, 2005). Frances (2000) favours the claim that ARIMA models are the most frequently used models for predictions of time series that can be statically transformed. Models are mainly used for short-term prediction if there are no explanatory data for the variable or if the model has poor predictive power. Predicting future stock market values based on both past and present data lines isare, therefore, one of the most demanded financial applications (Stehel and Vochozka, 2016).

The fact that the financial prediction is one of the most important areas of research where the investor's money is at stake due to the rise or fall in stock prices that are unpredictable and vague is also mentioned by Mohapatra et al. (2018). Furthermore, using neural networks in the prediction of stock price developments says that, essentially, because the demand for stock markets grew unprecedentedly, its predictions are even more exciting but at the same time more demanding. In the prediction of future stock prices, the models based on the artificial neural network (ANN) are taken into account. ANN development led investors to hope for the best predictions, as networks involved large machine learning abilities such as classification and prediction (Horák et al., 2018). ANNs have many advantages compared to ordinary methods. They are able to analyse complicated patterns fast and with high accuracy. ANNs are flexible in their use itself (Vochozka and Krulický, 2018). The disadvantage of neural networks is their request for large data about the sample because to create such a huge amount of data it is necessary to carry out a lot of sample observations, which is very uncomfortable for the users. The next main 
disadvantage is the topology optimization process in hidden layers, which is timeconsuming, and complicates the computing process (Rowland and Vrbka, 2016). Neural networks are therefore considered to be a highly effective method for collecting, analyzing and predicting data, and therefore their use is possible in a number of complex situations or in solving complex problems (Vochozka and Machová, 2018). The artificial neural network is capable of fully detecting the complex relationship between investors and price fluctuations and, therefore, these networks are also being used to predict the share prices of individual companies (Wu et al., 2015). Other research approaches in the area of financial application are also explored by other models such as Bio-inspired Computing, fuzzy network model, etc. With regard to statistical measures, technical indicators and basic indicators (Vochozka et al., 2018).

Golamaryami et al. (2016) deal with the use of ANNs, which can deal with data and nonlinear parameters to predict the price of stocks the next day. The described research has taught the proposed ANN a meta-heuristic bat algorithm that has rapid and strong convergence. The recommended method was used to predict prices for the first time. This contribution used a seven-year data set from private banks to prove the effectiveness of the proposed method. After pre-processing, three types of ANN (backpropagation - ANN, particle swarm optimization - ANN and bat-ANN) were used to be able to predict the stock price. Another example of using neural networks to predict the development of stock prices is research focusing on the design and optimization of artificial neural networks (especially nonlinear autoregressive networks) and their subsequent use in predictive application in time series of stock markets. Hortai (2016) demonstrates that a properly constructed artificial neural network can support trading in financial markets through the ability to predict stock price trends.

The prediction of stock prices on the Czech market is interesting to Svoboda (2016), who deals with stochastic modeling and short-term prediction of stock price developments on the Czech stock market. The aim of his research is to create such models that can be used to create automated business strategies that will defeat the market. As Svoboda (2016) explains, the reliability of these models is validated on three highly liquid stocks on the stock exchange, those of 02, ČEZ and KB, for seven years during 2006-2012. The so-called Markovov chain analysis was used for modeling. Svoboda (2016) also describes that in these models, the state space is defined based on cumulative daily changes in stock price and the so-called state space model with eight states is used. The state space is parametrically defined as a multiple of the standard deviation of daily returns for each stock. Altogether, a total of 14 parameters were calculated and for each parameter, nine business strategies for all stocks were used. This means that 378 business strategies have been calculated.

Long-term and, first of all, accurate predictions of stock price developments are very difficult due to the impact of economic, environmental and other factors (Vochozka, 2017). This is taken into account by Nie and Jin (2016), who have taken advantage of the effective prediction of long-term time series to plan an investment strategy and gain more profit. In his article, the so-called Exponentially Segmented Formula (ESP) is introduced 
and used to predict volatility of the different stock data over five future prediction intervals. The new characteristic of stock price formation over a sub-fund, called the interval gradient, can characterize stock price fluctuations over a certain period. MSE Cumulative Distribution Function (CDF) was compared to MMSE-BC and SVR values. During the research, it was concluded that the developed interval gradient may capture the more complex dynamics of stock price trends. The average stock price can then be predicted relatively accurately at certain time intervals, with multiple average values in time intervals being used over long-term intervals. Thus, the prediction of the long-term stock price becomes more accurate and prevents the development of cumulative errors (Nie and Jin, 2016).

Guo et al. (2015) propose and implement a hybrid model that combines two-way analysis of two component elements ((2D) 2 PCAs) and the Radical Base Functional Neural Network (RBFNN) to predict the behavior of stock markets. Guo et al. (2015) explain that 36 technical variables are first selected as input elements and a sliding window is used to obtain model input data. Furthermore, the (2D) 2 PCA is used to reduce the range of data and extract its own properties. Finally, the aforementioned RBFNN receives data processed by (2D) 2 PCAs to predict the price or movement of stocks the following day. The proposed model is used on the Shanghai stock market index and experiments show that the model is at a good level.

This contribution is based on the article of Vrbka and Rowland (2017). The aim of this article was to predict the future development of the stock prices of ČEZ, a.s. on the Prague Stock Exchange using neural networks.

In the methodology, the author described the main activity and position of ČEZ, a.s. in the energy market. He also dealt with the data used to calculate the neural structure able to predict the future development of ČEZ stock prices. Price data on stock prices was used from between February 2, 2012 and October 9, 2017, amounting to a total of 1,442 records. The data came from the Prague Stock Exchange database. These were the final prices of each day on which the stocks of the company were traded during that period. To determine the neural structure, the Statistica software in version 12 by DELL was used. Multilayer Perceptron Neural Networks and Neural Networks of Basic Radial Functions were generated. A detailed description is provided by Vochozka et al. (2017).

This article has the ambition to work further using the contribution of Vrbka and Rowland (2017):

1. Since the publication of the paper, information about the development of ČEZ's prices is already known within the time period of 62 trading days of the prediction. We can therefore assess how accurate the prediction of future stock price developments in the paper is.

2. We will generate new neural structures that will take into account stock price developments in the 62 trading days following 9. October 2017.

The methodology of this article will be identical to that of Vrbka and Rowland (2017). However, the data file will be different. For this article, we will use data from the Prague 
Stock Exchange on ČEZ stock prices for the period from February 2, 2012 to January 8, 2018, namely 1,504 final price data entries for each trading day. In addition, the results of Vrbka and Rowland (2017) will be used.

\section{Results}

Statistics of the data file are listed in Table 1.

Tab. 1: Data input statistics for the data file

\begin{tabular}{|l|r|}
\hline \multicolumn{1}{|c|}{ Statistic } & Stock price (Output) \\
\hline Minimum (Training) & 364.1 \\
\hline Maximum (Training) & 840 \\
\hline Average (Training) & 549.2319 \\
\hline Standard deviation (Training) & 113.5939 \\
\hline Minimum (Testing) & 372 \\
\hline Maximum (Testing) & 838.7 \\
\hline Average (Testing) & 542.9668 \\
\hline Standard deviation (Testing) & 117.6344 \\
\hline Minimum (Validation) & 376.1 \\
\hline Maximum (Validation) & 815 \\
\hline Average (Validation) & 552.0947 \\
\hline Standard & 203.2175 \\
\hline Minimum (Overall) & 364.1 \\
\hline Maximum (Overall) & 840 \\
\hline Average (Overall) & 548.7184 \\
\hline Standard deviation (Overall) & 114.4234 \\
\hline
\end{tabular}

Source: Authors.

Validation of the results in the article by Vrbka and Rowland (2017)

In order to make a comparison, we need to summarize the results achieved in the contribution by Vrbka and Rowland (2017). The contribution presents five preserved neural structures of 10,000 generated (see Table 2).

Tab. 2: Overview of preserved neural networks (2017)

\begin{tabular}{|l|l|c|c|c|c|c|c|c|c|c|}
\hline $\begin{array}{c}\text { Network } \\
\text { name }\end{array}$ & $\begin{array}{c}\text { Training } \\
\text { perform. }\end{array}$ & $\begin{array}{c}\text { Testing } \\
\text { perform. }\end{array}$ & $\begin{array}{c}\text { Validation } \\
\text { perform. }\end{array}$ & $\begin{array}{c}\text { Training } \\
\text { error }\end{array}$ & $\begin{array}{c}\text { Testing } \\
\text { error }\end{array}$ & $\begin{array}{c}\text { Validation } \\
\text { error }\end{array}$ & $\begin{array}{c}\text { Training } \\
\text { algorithm }\end{array}$ & $\begin{array}{c}\text { Error } \\
\text { function }\end{array}$ & $\begin{array}{c}\text { Activ. of } \\
\text { hidden layer }\end{array}$ & $\begin{array}{c}\text { Output activ. } \\
\text { function }\end{array}$ \\
\hline $\begin{array}{l}\text { MLP } \\
1-2-1\end{array}$ & 0.997742 & 0.997614 & 0.997649 & 30.86339 & 31.51797 & 27.94235 & $\begin{array}{c}\text { BFGS (Quasi- } \\
\text { Newton) 86 }\end{array}$ & $\begin{array}{c}\text { Sum of } \\
\text { squares }\end{array}$ & Tanh & Identity \\
\hline $\begin{array}{l}\text { MLP } \\
1-2-1\end{array}$ & 0.997759 & 0.997617 & 0.997649 & 30.62266 & 31.4799 & 27.91572 & $\begin{array}{c}\text { BFGS (Quasi- } \\
\text { Newton) 504 }\end{array}$ & $\begin{array}{c}\text { Sum of } \\
\text { squares }\end{array}$ & Tanh & Identity \\
\hline $\begin{array}{l}\text { MLP } \\
1-7-1\end{array}$ & 0.997778 & 0.997605 & 0.997648 & 30.36993 & 31.63007 & 27.95397 & $\begin{array}{l}\text { BFGS (Quasi- } \\
\text { Newton) 123 }\end{array}$ & $\begin{array}{c}\text { Sum of } \\
\text { squares }\end{array}$ & Logistic & Tanh \\
\hline $\begin{array}{l}\text { MLP } \\
1-5-1\end{array}$ & 0.997778 & 0.997597 & 0.997648 & 30.37189 & 31.74181 & 27.91681 & $\begin{array}{l}\text { BFGS (Quasi- } \\
\text { Newton) 143 }\end{array}$ & $\begin{array}{c}\text { Sum of } \\
\text { squares }\end{array}$ & Tanh & Tanh \\
\hline $\begin{array}{l}\text { MLP } \\
1-4-1\end{array}$ & 0.997774 & 0.997603 & 0.997649 & 30.41342 & 31.67233 & 27.89103 & $\begin{array}{c}\text { BFGS (Quasi- } \\
\text { Newton) 88 }\end{array}$ & $\begin{array}{c}\text { Sum of } \\
\text { squares }\end{array}$ & Logistic & Tanh \\
\hline
\end{tabular}

Source: Vrbka and Rowland (2017). 
The paper presented neural structures that showed the best characteristics - i.e. the best performance at minimum error. All retained networks are multilayered perceptron artificial neural networks. They use two to seven neurons in the hidden layer. Their performance is characterized in all datasets (training, testing and validation) with a correlation coefficient higher than 0.997 . This is an excellent result. The networks were created based on the Quasi-Newton training algorithm. The sum of smallest squares was used as the error function. The networks use the logistic function and hyperbolic tangens to activate hidden neurons. To activate the output layer of the neural network, they use hyperbolic tangents or an identity function.

Based on the results described, it is clear that the time series alignment (ČEZ stock prices) should be almost perfect. Time series alignment using neural networks is the subject of Graph 1.

Graph 1: Time series with prediction for 62 trading days

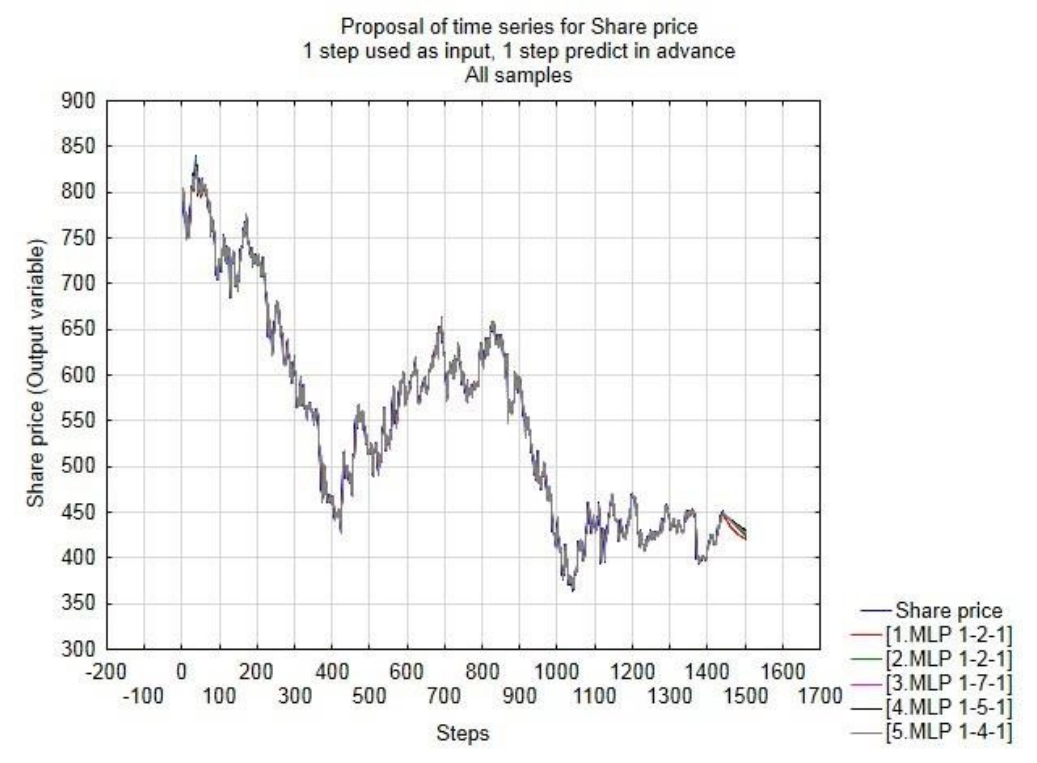

Source: Vrbka and Rowland (2017).

The figure shows the time series alignment using neural networks and then the prediction of the stock price of the assessed company over the next 62 trading days. In the time series alignment interval, the differences between actual price developments and time series alignment results are totally indistinguishable. In addition, all retained neural networks show approximately the same results. They begin to appear different only at the time interval of prediction (see Graph 2). 
Graph 2: Prediction of the next 62 tr0ading days

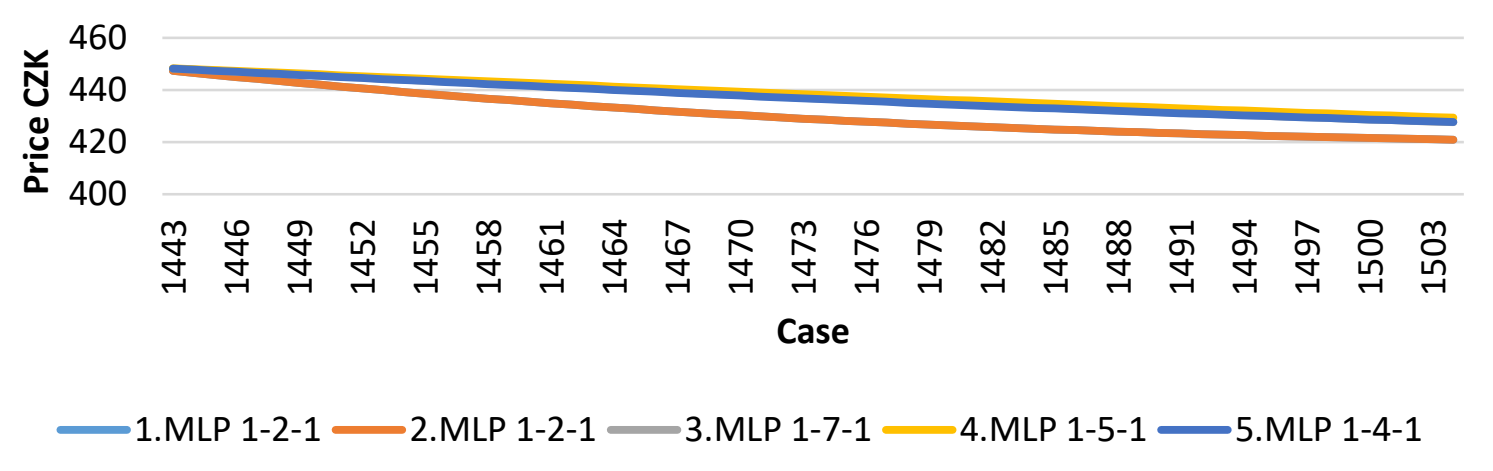

Source: Vrbka and Rowland (2017).

Graph 2 provides the development of predicted prices for 62 future trading days. The results do not differ much at the time of the first prediction. After 62 business days, the prediction differs by less than $10 \mathrm{CZK}$, which can be considered as a great result.

Vrbka and Rowland (2017) summarize the result as follows: "By statistical interpretation of the results, it has been found that they are all usable in practice. The differences are entirely minimal at the value of one stock. Nevertheless, with the greatest difference between the maximum and minimum predictions, the deviation is $2.26 \%$. This may not be significant at the price of one share. However, when you buy or sell a large number of stocks, the difference may appear to be significant. I therefore recommend that two networks be used in practice: MLP 1-2-1 (first network) and MLP 1-5-1 (fourth network). The first neural network always represents a pessimistic, minimal prediction (as does the second neural network). The fourth network then corresponds to an optimistic, maximum prediction. The reality should be that of the difference between the optimistic and the pessimistic prediction."

\section{Comparison of actual price development and results of the contribution by Vrbka and Rowland (2017)}

Graph 3 provides a comparison of the development of ČEZ stock price predicted by neural networks by Vrbka and Rowland (2017) and actual stock price developments. 
Graph 3: Comparison of time series by Vrbka and Rowland (2017) and actual stock prices

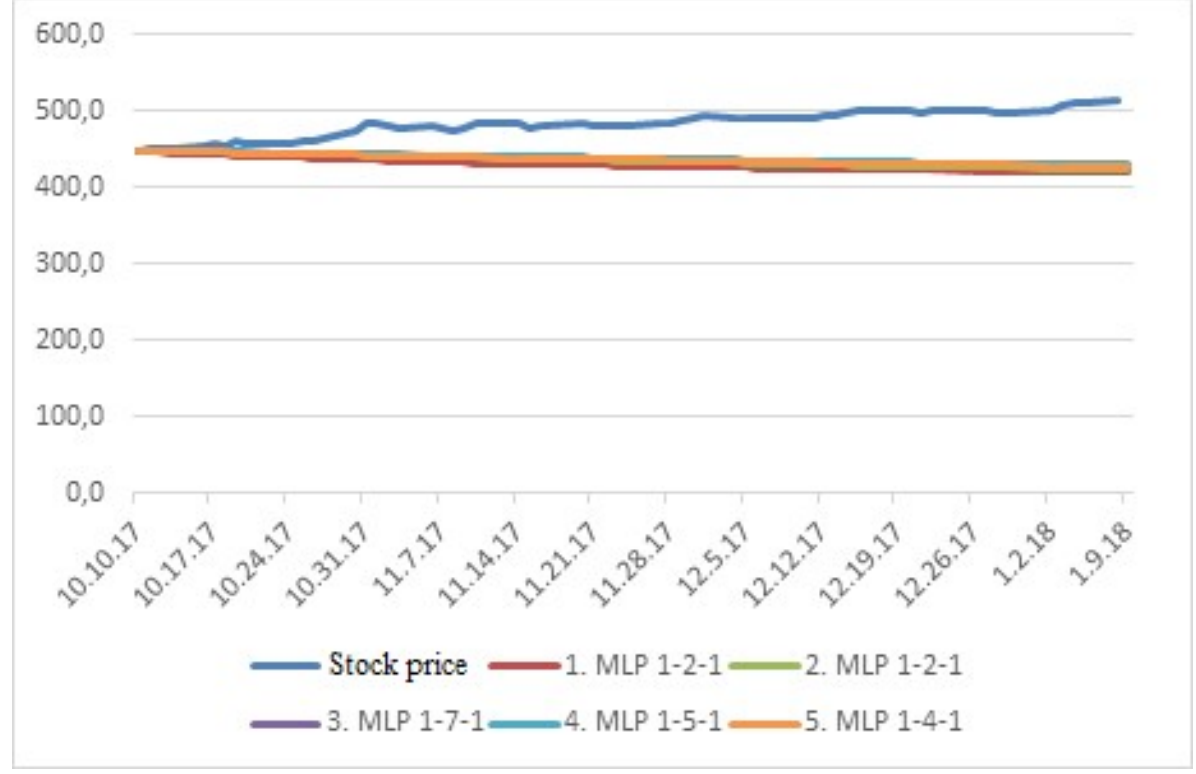

Source: Vrbka and Rowland (2017).

It can be seen from the graph that the prediction of development using artificial neural structures was very pessimistic. In fact, the stock price is approaching the prediction only in the early days, let's say in the first trading week of the predicted period. In the next period, the imaginary scissors became more and more open. On 5 December 2017, the price of one ČEZ share was close to CZK 500 each. On the 62 nd day of the forecast, i.e. 8 January 2018, even the value of CZK 500 was significantly exceeded by the share price of ČEZ. In detail, but only on selected days, Table 3 shows the development of predictions and actual stock prices.

Tab. 3: Comparison of actual price developments of stock prices and neural networks by Vrbka and Rowland (2017)

\begin{tabular}{|c|c|c|c|c|c|c|c|c|c|c|c|c|}
\hline \multirow[b]{2}{*}{ Date } & \multirow[b]{2}{*}{$\begin{array}{l}\text { Stock } \\
\text { price }\end{array}$} & \multicolumn{5}{|c|}{ Stock prices } & \multicolumn{5}{|c|}{ Residue } & \multirow[b]{2}{*}{$\begin{array}{l}\text { Max. } \\
\text { residue }\end{array}$} \\
\hline & & $\begin{array}{c}\text { 1. MLP } \\
1-2-1\end{array}$ & $\begin{array}{c}2 . \text { MLP } \\
1-2-1\end{array} \mid$ & $\begin{array}{c}\text { 3. MLP } \\
1-7-1\end{array}$ & $\begin{array}{l}\text { 4. MLP } \\
1-5-1\end{array}$ & $\begin{array}{c}\text { 5. MLP } \\
1-4-1\end{array}$ & 1. & 2. & 3. & 4. & 5. & \\
\hline & 8.9 & & & 0.21 & & & 1.5 & 0.7 & 0.7 & 0.6 & 0.7 & 1.5 \\
\hline 24. & 8.2 & \begin{tabular}{|l}
439.91 \\
\end{tabular} & 444.35 & \begin{tabular}{|l|l|}
44.33 \\
\end{tabular} & 444.99 & 441 & 9.0 & 4. & 4.6 & 3.9 & 4.7 & 9.0 \\
\hline 07.11 .17 & 477.7 & 433.80 & 440.27 & 440.58 & 441.67 & \begin{tabular}{|l|l}
40.39 \\
\end{tabular} & 15.1 & 8.6 & 8.3 & 7.2 & 8.5 & 15.1 \\
\hline 22.1 & 480.0 & 429.03 & 436.04 & 437.02 & 438.43 & 436.79 & 19.9 & 12.9 & 11.9 & 10.5 & 12.1 & 9.9 \\
\hline & 490.4 & 425.46 & 431.77 & 433.69 & 435.31 & 433.50 & 23.4 & 17.1 & 15.2 & 13.6 & 15.4 & 23.4 \\
\hline 20.12 .17 & 499.0 & 422.88 & 427.61 & 430.65 & 432.38 & 430.55 & 26.0 & 21.3 & 18.2 & 16.5 & 18.4 & 26.0 \\
\hline 08.01 .18 & 513.0 & 421.06 & 423.80 & \begin{tabular}{|l|l}
427.92 \\
\end{tabular} & 429.66 & \begin{tabular}{|l}
427.96 \\
\end{tabular} & 27.8 & 25.1 & 21.0 & 19.2 & 20.9 & 27.8 \\
\hline
\end{tabular}

Source: Vrbka and Rowland (2017); Authors' calculations.

The table shows the actual price development of the ČEZ share in the column "Stock price". Then, prediction is displayed using the generated neural networks by Vrbka and Rowland (2017). Five columns below "Residue" are used to calculate the difference between the actual stock price and the predictions, each for each neural network 
separately. The last column shows the biggest difference between the actual share price and the prediction. In all cases, this is the difference between the actual stock price and network number 1, i.e. MLP 1-2-1. The development of residues is evident from Graph 4.

Graph 4: Development of residues of networks by Vrbka and Rowland (2017)

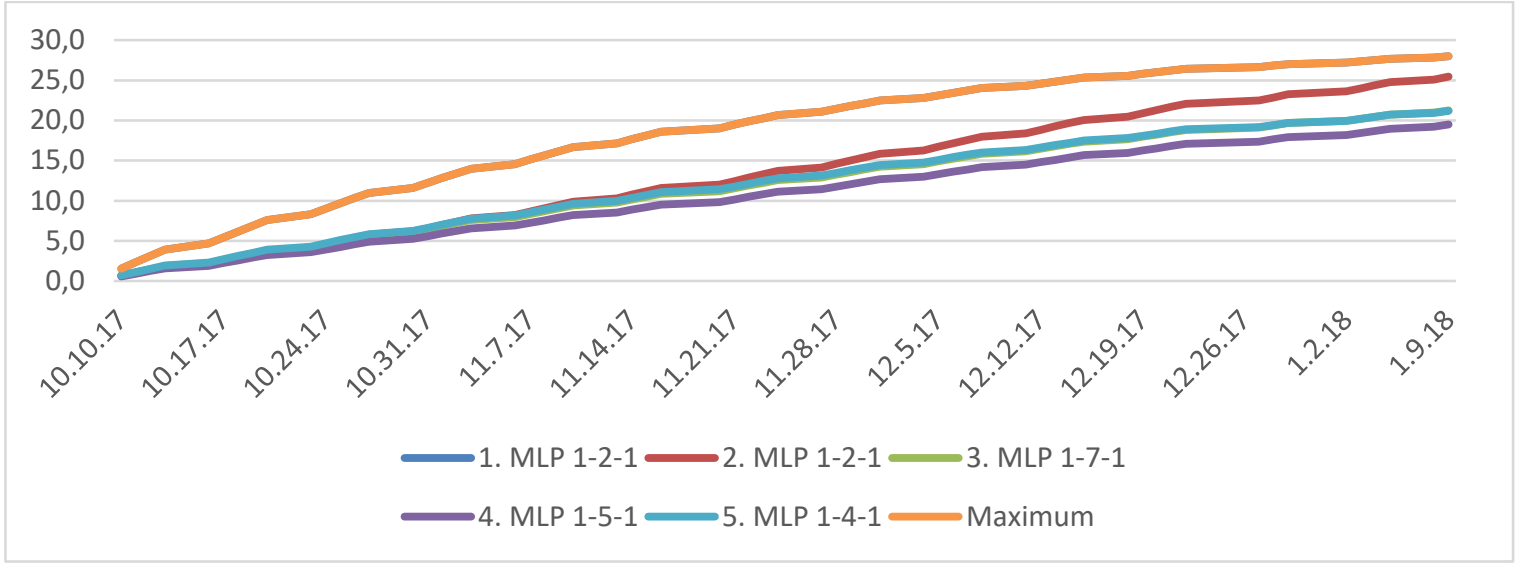

Source: Vrbka and Rowland (2017); Authors' calculations.

The picture shows a growing residue development in time. The absolute minimum difference between the predictions and the actual price of the share is 10 October 2017 . On the other hand, the largest residue is observed on 9 January 2018, when the maximum residue is at a limit of CZK 28 per share, which is approximately $5.46 \%$ of the share price. On the contrary, the minimum residue is below $20 \mathrm{CZK}$ per share. This difference amounts to less than 3.9\%. This difference is offered by a prediction using the 4th neural network, i.e. MLP 1-5-1. It is therefore a question of whether such a difference is sufficient. On the one hand, the difference seems to be minimal. On the other hand, if we imagine the role of an investor (or perhaps a speculator) who works with a change in the stock price each day, i.e. even a tenth of a CZK, it is a fairly large difference. From my point of view, however, the directives of the development curves are absolutely essential. In fact, the stock price grew. However, all retained neural networks assumed a fall in stock prices. Therefore, if we disregard the difference between reality and predictions, we can not rely even on the basic prediction of the future price - growth or decline.

\section{Newly generated neural structures}

The aim of this paper, along with the evaluation of the outputs by Vrbka and Rowland (2017), is, following the same methodology, to generate new neural networks that will align the time series of stock prices. The results are shown in Table 4. 
Tab. 4: Newly generated neural structures

\begin{tabular}{|l|c|c|c|c|c|c|c|c|c|c|}
\hline $\begin{array}{l}\text { Network } \\
\text { name }\end{array}$ & $\begin{array}{c}\text { Training } \\
\text { perf. }\end{array}$ & $\begin{array}{c}\text { Testing } \\
\text { perf. }\end{array}$ & $\begin{array}{c}\text { Validation } \\
\text { perf. }\end{array}$ & $\begin{array}{c}\text { Training } \\
\text { error }\end{array}$ & $\begin{array}{c}\text { Testing } \\
\text { error }\end{array}$ & $\begin{array}{c}\text { Validation } \\
\text { error }\end{array}$ & $\begin{array}{c}\text { Training } \\
\text { algorithm }\end{array}$ & $\begin{array}{c}\text { Error } \\
\text { function }\end{array}$ & $\begin{array}{c}\text { Activ. of } \\
\text { hidden }\end{array}$ & $\begin{array}{c}\text { Output } \\
\text { activ. }\end{array}$ \\
\hline $\begin{array}{l}\text { RBF } \\
1-30-1\end{array}$ & 0.9867 & 0.9860 & 0.9889 & 168.6022 & 196.947 & 146.1548 & RBFT & $\begin{array}{c}\text { Sum of } \\
\text { squares }\end{array}$ & Gauss & Identity \\
\hline $\begin{array}{l}\text { RBF } \\
1-28-1\end{array}$ & 0.9876 & 0.9863 & 0.9894 & 157.2429 & 188.4303 & 139.0066 & RBFT & $\begin{array}{c}\text { Sum of } \\
\text { squares }\end{array}$ & Gauss & Identity \\
\hline $\begin{array}{l}\text { RBF } \\
1-28-1\end{array}$ & 0.9898 & 0.9892 & 0.9897 & 130.0019 & 150.9605 & 135.9292 & RBFT & $\begin{array}{c}\text { Sum of } \\
\text { squares }\end{array}$ & Gauss & Identity \\
\hline $\begin{array}{l}\text { RBF } \\
1-29-1\end{array}$ & 0.9861 & 0.9858 & 0.9890 & 175.7906 & 198.9865 & 145.1187 & RBFT & $\begin{array}{c}\text { Sum of } \\
\text { squares }\end{array}$ & Gauss & Identity \\
\hline $\begin{array}{l}\text { MLP } \\
1-20-1\end{array}$ & 0.9876 & 0.9880 & 0.9889 & 156.7676 & 165.9484 & 146.8933 & $\begin{array}{l}\text { BFGS (Quasi- } \\
\text { Newton) } 603\end{array}$ & $\begin{array}{c}\text { Sum of } \\
\text { squares }\end{array}$ & Tanh & Exponential \\
\hline
\end{tabular}

Source: Authors.

For the calculation of neural structures, the original data set was extended by 62 further trading days. The result is completely different at first glance. Of the 10,000 generated neural structures, five artificial neural structures with the best characteristics were preserved. Among these are four structures based on fuzzy logic, namely artificial neural networks of basic radial function (RBF). Only one is a multilayer perceptron neural network (MLP). All preserved networks use the sum of smallest squares as the error function. RBF networks were generated using the RBFT algorithm, MLP using QuasiNewton. RBF networks use the Gaussian curve to activate the hidden neuron layer, and also use the identity function to activate the output layer of the neurons. MLP activates hidden neurons using hyperbolic tangens, the output layer of neurons is then activated by exponential function. Table 5 provides a summary of the performance of preserved neural structures.

Tab. 5: Correlation coefficients of newly generated neural structures

\begin{tabular}{|c|r|r|r|}
\hline \multirow{2}{*}{$\begin{array}{c}\text { Neural } \\
\text { network }\end{array}$} & \multicolumn{3}{|c|}{ Stock price } \\
\cline { 2 - 4 } & Training & Testing & Validation \\
\hline 1.RBF 1-30-1 & 0.9867 & 0.985978 & 0.988928 \\
\hline 2.RBF 1-28-1 & 0.987601 & 0.986325 & 0.989411 \\
\hline 3.RBF 1-28-1 & 0.98976 & 0.989157 & 0.989721 \\
\hline 4.RBF 1-29-1 & 0.986129 & 0.985746 & 0.988945 \\
\hline 5.MLP 1-20-1 & 0.987639 & 0.988043 & 0.988877 \\
\hline
\end{tabular}

Source: Authors.

The table shows that the performance measured by the correlation coefficient ranges across all networks and all data sets (training, test, validation) are at a value of nearly 0.986 and higher. For the interpretation of correlation coefficients results, see Table 6. 
Tab. 6: Data set statistics (stock price)

\begin{tabular}{|l|r|r|r|r|r|}
\hline \multicolumn{1}{|c|}{ Statistic } & \multicolumn{1}{c|}{$\mathbf{1 . R B F}$} & \multicolumn{1}{c|}{$\mathbf{2 . R B F}$} & \multicolumn{1}{c|}{$\mathbf{3 . R B F}$} & \multicolumn{1}{|c|}{$\mathbf{4 . R B F}$} & \multicolumn{1}{c|}{$\mathbf{5 . M L P}$} \\
& $\mathbf{1 - 3 0 - 1}$ & $\mathbf{1 - 2 8 - 1}$ & $\mathbf{1 - 2 8 - 1}$ & $\mathbf{1 - 2 9 - 1}$ & $\mathbf{1 - 2 0 - 1}$ \\
\hline Minimum prediction (Training) & \multicolumn{1}{c|}{371.5924} & \multicolumn{1}{c|}{397.453} & 375.1882 & 400.8816 & 404.6215 \\
\hline Maximum prediction (Training) & 799.6237 & 796.9626 & 813.9006 & 808.7179 & 814.2319 \\
\hline Minimum prediction (Testing) & 371.7026 & 397.493 & 376.1742 & 400.8925 & 404.9563 \\
\hline Maximum prediction (Testing) & 799.4127 & 796.8768 & 813.901 & 808.5803 & 814.2064 \\
\hline Minimum prediction (Validation) & 371.4968 & 397.6789 & 375.1709 & 401.1822 & 404.6574 \\
\hline Maximum prediction (Validation) & 799.6393 & 796.9603 & 811.7112 & 808.4986 & 812.8466 \\
\hline Minimum residue (Training) & -63.2352 & -52.0334 & -57.1139 & -59.6718 & -63.2495 \\
\hline Maximum residue (Training) & 55.4007 & 47.6043 & 55.6073 & 67.0185 & 54.7311 \\
\hline Minimum residue (Testing) & -54.1029 & -51.5238 & -56.2782 & -49.8032 & -46.1096 \\
\hline Maximum residue (Testing) & 51.5022 & 47.3868 & 51.3216 & 47.2056 & 44.3409 \\
\hline Minimum residue (Validation) & -54.0977 & -52.6699 & -49.8544 & -44.6101 & -46.4877 \\
\hline Maximum residue (Validation) & 49.1433 & 41.5352 & 40.3405 & 51.3943 & 48.1361 \\
\hline Minimum standard residue (Training) & -4.87 & -4.1495 & -5.0092 & -4.5006 & -5.0516 \\
\hline Maximum standard residue (Training) & 4.2666 & 3.7963 & 4.877 & 5.0547 & 4.3713 \\
\hline Minimum standard residue (Testing) & -3.8552 & -3.7535 & -4.5805 & -3.5306 & -3.5794 \\
\hline Maximum standard residue (Testing) & 3.6699 & 3.4521 & 4.177 & 3.3464 & 3.4421 \\
\hline Minimum standard residue (Validation) & -4.4748 & -4.4673 & -4.2761 & -3.7031 & -3.8356 \\
\hline Maximum standard residue (Validation) & 4.065 & 3.5229 & 3.4601 & 4.2663 & 3.9716 \\
\hline
\end{tabular}

Source: Authors.

The table presents basic statistics of all data sets of stored neural network data. The table shows minimal differences between individual neural networks. We would optically see that all preserved neural networks are usable in practice. Probably better to help us identify the best neural network will be Graph 5 .

Graph 5: Time series alignment using newly generated neural networks

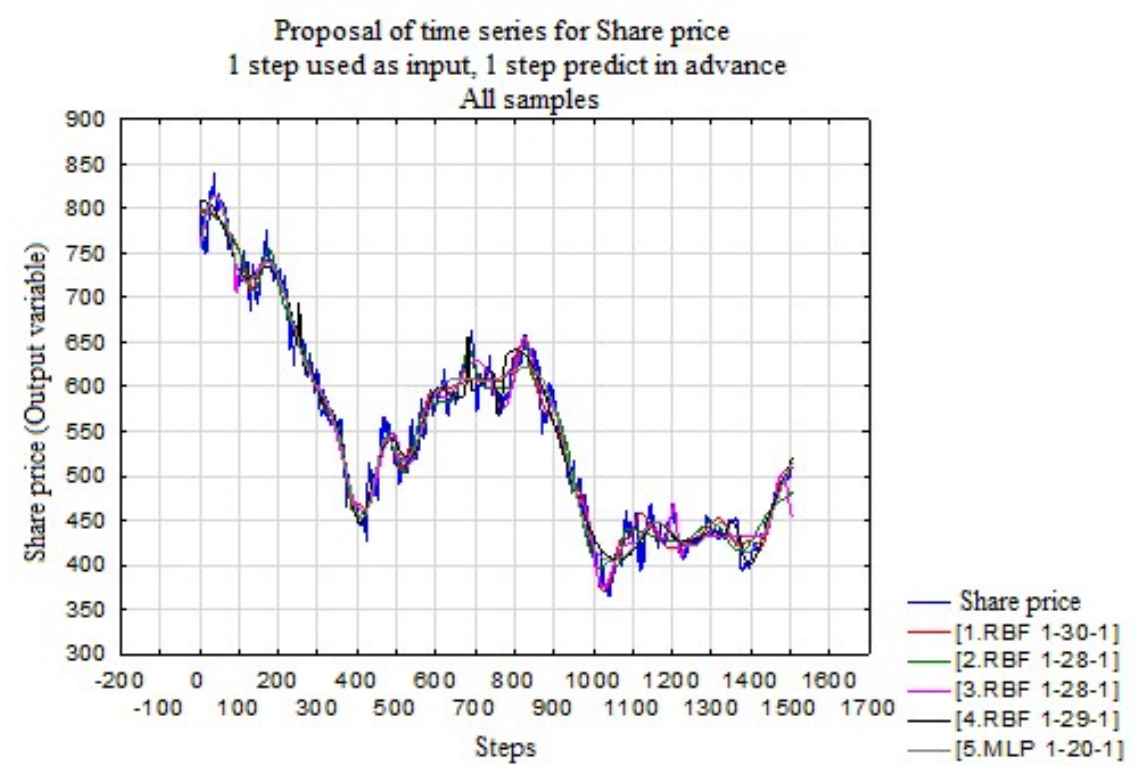

Source: Authors. 
The figure shows the actual development of the stock prices (blue curve) and the aligned time series using preserved neural networks. In this case, the development is not as clear as in the case of Vrbka and Rowland (2017), where the pattern of aligned time series almost coincided with the development of the real stock prices. Since we know the actual development of the stock prices, we will leave the decision of which of the preserved neural networks predicts the stock price best on the next part of the contribution.

\section{Comparison of newly generated structures and structures by Vrbka and Rowland (2017)}

In the next part of the paper we will focus on the last 62 trading days of the data file. This is a period used for prediction of the development of the stock prices of ČEZ by Vrbka and Rowland (2017). Graph 6 shows stock price developments over the monitored period, as well as predictions using networks by Vrbka and Rowland (2017) and newly generated networks (however this is not a prediction, but an aligned time series in that period).

Graph 6: Comparison of development predicted by neural networks and actual stock price developments of ČEZ

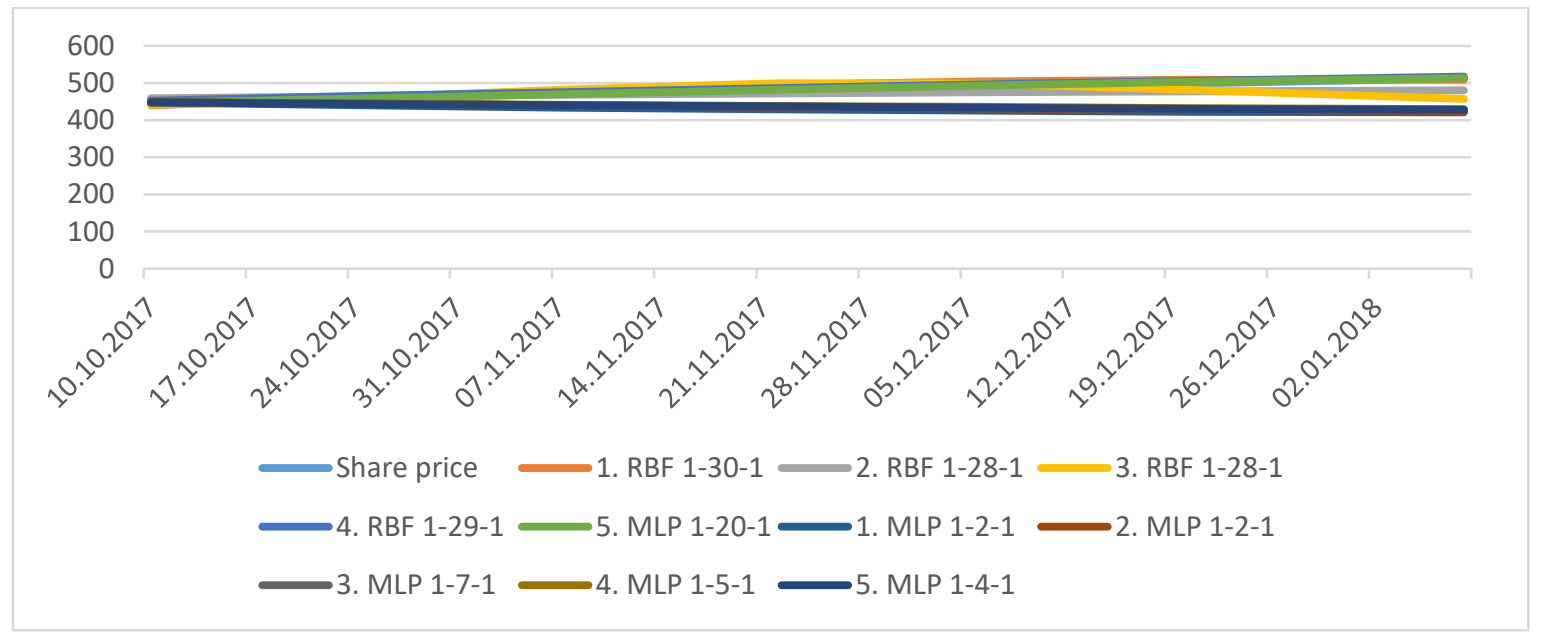

Source: Authors.

It can be seen from the figure that the networks from the contribution of Vrbka and Rowland (2017) have the time series directive as decreasing. From the preserved new neural networks, the third network, ie RBF 1-28-1, has the directive first as growing and then decreasing. Other newly generated and preserved networks have a growing directive. This means they are following the development of the real stock prices. Specific values of individual networks by Vrbka and Rowland (2017) and new networks, are offered by Table 7 . 
Tab. 7: Selected values of prediction and actual stock prices

\begin{tabular}{|c|c|c|c|c|c|c|c|c|c|c|c|}
\hline Date & $\begin{array}{l}\text { Stock } \\
\text { price }\end{array}$ & \begin{tabular}{|l}
$1 . \mathrm{RBF}$ \\
$1-30-1$
\end{tabular} & $\begin{array}{l}\text { 2. RBF } \\
1-28-1\end{array}$ & $\begin{array}{l}3 . \text { RBF } \\
1-28-1\end{array}$ & \begin{tabular}{|l|}
$4 . \mathrm{RBF}$ \\
$1-29-1$
\end{tabular} & \begin{tabular}{|l} 
5. MLP \\
$1-20-1$
\end{tabular} & \begin{tabular}{|c|}
1. MLP \\
$1-2-1$
\end{tabular} & \begin{tabular}{|c|}
2. MLP \\
$1-2-1$
\end{tabular} & \begin{tabular}{|c|} 
3. MLP \\
$1-7-1$
\end{tabular} & $\begin{array}{c}\text { 4. MLP } \\
1-5-1\end{array}$ & $\begin{array}{c}\text { 5. MLP } \\
1-4-1\end{array}$ \\
\hline 10.10 .17 & 448.9 & 4 & .91 & 441.47 & 2.23 & 4466.75 & 447.36 & 448.24 & 448.21 & 448.34 & 448.20 \\
\hline 24.10 .17 & 458.2 & 459.46 & 464.15 & 458.84 & \begin{tabular}{|l|}
464.49 \\
\end{tabular} & \begin{tabular}{|l|l|}
457.82 \\
\end{tabular} & 439.91 & 444.35 & 444.33 & 444.99 & 444.22 \\
\hline 07.11 .17 & 477.7 & 479.28 & 468.33 & 481.87 & 475.52 & \begin{tabular}{|l|}
469.46 \\
\end{tabular} & 433.80 & 440.27 & 440.58 & 441.67 & 440.39 \\
\hline 22.11 .17 & 480.0 & 495.67 & 471.88 & 499.45 & 486.42 & 481.88 & 429.03 & 436.04 & 437.02 & 438.43 & 436.79 \\
\hline 06.12 .17 & 490.4 & 504.66 & 474.65 & 498.39 & 496.21 & \begin{tabular}{|l|}
492.88 \\
\end{tabular} & 425.46 & 431.77 & 433.69 & 435.31 & 433.50 \\
\hline 20.12 .17 & 499.0 & 508.46 & 477.21 & 482.04 & \begin{tabular}{|l|}
505.86 \\
\end{tabular} & 502.86 & 422.88 & 427.61 & 430.65 & 432.38 & 430.55 \\
\hline 08.01 .18 & 513.0 & 508.99 & 480.37 & 457.39 & \begin{tabular}{|l|}
517.38 \\
\end{tabular} & 513.24 & 421.06 & 423.80 & 427.91 & 429.66 & 427.96 \\
\hline
\end{tabular}

Source: Authors.

It can be seen from the table that the original neural networks almost accurately predicted the development on October 10, 2017. The differences between the networks and the reality were within the range of single-digit CZK to tenths of CZK (at least 0.6 CZK per share). On the contrary, new networks predicted the price higher than even by more than 10 CZK, respectively about 9 CZK lower. On October 24, 2017 the situation is changing. Original neural networks predict a decline in ČEZ's stock price. New networks predict a rise in price. Even the new network number 3. RBF 1-28-1 is approaching the correct value of the difference of 0.6 CZK. Further development is fairly unambiguous. The original neural networks are moving away from the actual value. From the new neural networks, in particular RBF 1-29-1 and MLP 1-20-1, can track the actual development. Both these networks are more or less able to copy the actual development. Graph 7 provides a detailed view of actual price and predicted development using original neural networks and time series alignment using new neural networks.

Graph 7: Comparison of selected predicted values and actual stock prices

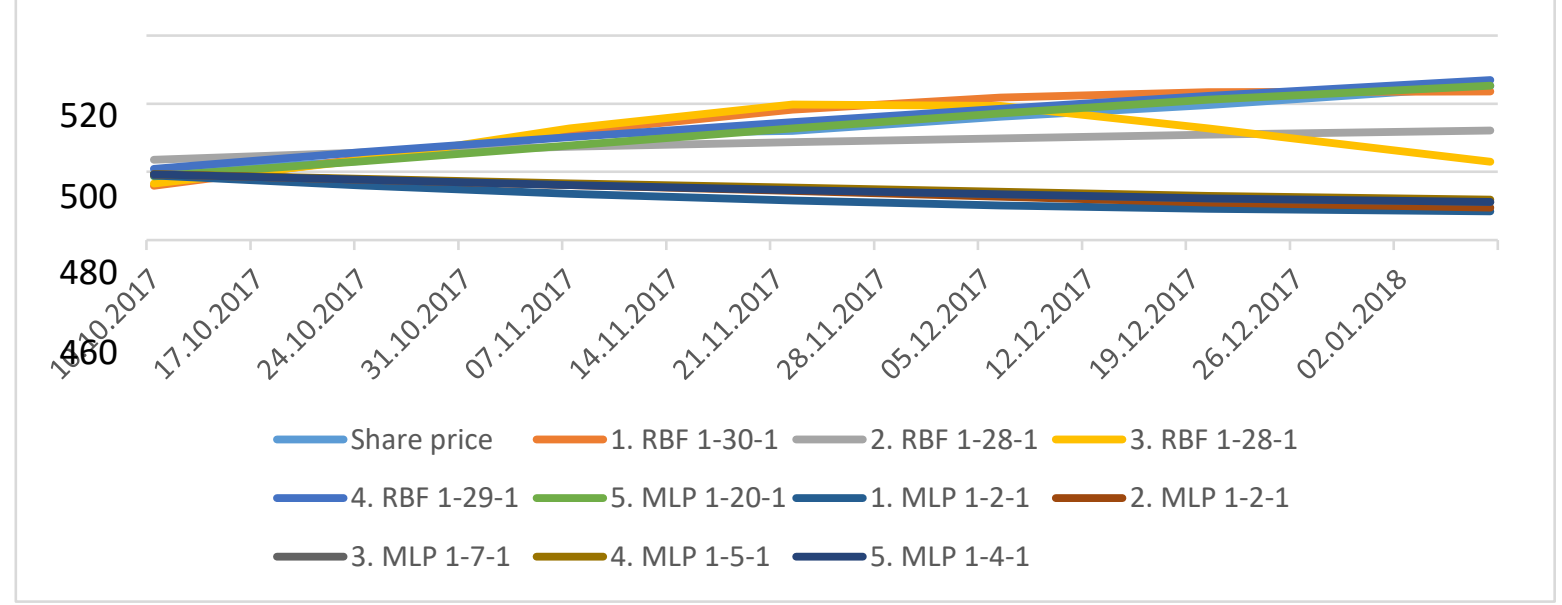

Source: Authors.

It is clear from Graph 7 that we can only consider the use of new networks 4 and 5 in practice. The original networks have completely failed. For new networks, the other structures differ in each prediction. 


\section{Conclusion}

The aim of this paper was to verify the prediction of the stock prices of ČEZ, a.s. on the Prague Stock Exchange. The main goal was decomposed into two sub-goals:

1. Evaluate accuracy of the prediction using neural networks of Vrbka and Rowland (2017) on stock price data that followed the time series used to calculate neural networks in the contribution of Vrbka and Rowland (2017).

2. Generate new neural structures that take account of stock price developments in the 62 trading days following 9 October 2017.

The aim of the paper was fulfilled. For sub-goal 1 we can state that:

1. The original neural networks predicted future development correctly for only the following day.

2. Over a longer period of time, the gap between predictions using the original networks and the actual stock prices increased over time.

3. The maximum difference between the prediction and the actual price was up to $5.46 \%$ of the share price.

4. The original neural networks were also wrong in the case of the curve of the future development of the share price of ČEZ.

5. We can summarize that the original neural networks are inappropriate to predict the evolution of ČEZ stock prices, even though they presented themselves with high performance in the training, testing and validation data sets.

For sub-goal 2 we can state that:

1. Optically, two new neural structures can be used in practice. Networks 4. RBF 129-1 and 5. MLP 1-20-1 can align time series to track actual price developments.

2. The practical use of new networks was not tested on data that did not enter the calculation. Therefore, it can not be estimated to what extent the predictions will be correct.

3. New networks show lower performance in all three sets of data using the same methodology.

It is certainly good to return to the lower performance of new networks. Since the same methodology for calculating neural structures has been applied, it can be assumed that lower performance can be due to two causes:

1. The construction of neural networks in Statistica is the result of estimation, iteration and, to some extent, even coincidence. It may be the result of the fact that neural structures can have many variants with given rules, and the software simply does not have to choose the appropriate structure because it simply does not test its parameters. If this fact were true, it would mean that we will reach different results even with the same data. The situation can be solved by higher computational power and by specifying a parameter about the number of generated neural networks at the level of all possible variants that may arise 
(including the most unlikely ones). However, it is a question of whether such a number is final.

2. We can assume that the development of ČEZ's stock prices before 9. October 2017 is extraordinary and, in fact, a turbulent in comparison to previous developments.

What should be the next step? Again three options are offered. All of them, however, assume a living artificial intelligence capable of learning with every next piece of information received:

1. We select the most successful preserved neural structure (in this case, either the structure 4 or 5). Subsequently, we will modify the weight of each neural link, by synapse, with each additional share price, so that we can get the best results each following day.

2. With each new piece of data, we will generate new neural structures able to predict stock price developments in the short term.

3. We will use neural structures only to predict the basic price, which will be subsequently corrected using causal prediction methods.

Finally, I would like to remind you that each model (i.e. the neural structure) is a simplification of reality, but we try to bring ourselves as close to reality as possible.

\section{References}

1. ETEMADI, H., A. AHMADPOUR and S. M. MOSHASHAEI, 2015. Earnings Per Share Forecast Using Extracted Rules from Trained Neural Network by Genetic Algorithm. Computational Economics. 46(1), 55-63.doi: https://doi.org/10.1007/s10614-014-9455-6

2. FRANCES, P. H. B. F., 2000. The Econometric Modelling of Financial Time Series. International Journal of Forecasting. 16(3), 426-427. doi: https://doi.org/10.1016/S0169-2070(00)00046-7

3. GOLMARYAMI, M., M. BEHZADI and M. AHMADZADEH, 2016. A hybrid method based on neural networks and a meta-heuristic bat algorithm for stock price prediction. Paper presented at: Conference Proceedings of 2015 2nd International Conference on Knowledge-Based Engineering and Innovation. Teheran, Iran, pp. 269-275.

4. GRODA, B., J. VRBKA, 2017. Prediction of stock price developments using the BoxJenkins method. Paper presented at: SHS Web of Conferences: Innovative Economic Symposium 2017 - Strategic Partnership in International Trade.2017. doi: https://doi.org/10.1051/shsconf/20173901007

5. GUO, Z. et al., 2015. A stock market forecasting model combining two-directional two-dimensional principal component analysis and radial basis function neural network. PLOS ONE. 10(4). doi: https://doi.org/10.1371/journal.pone.0122385

6. HORÁK, J., M. VOCHOZKA and V. MACHOVÁ, 2018. Evaluation of transport and forwarding companies by means neural networks. Paper presented at: Reviewed 
Proceedings of the Interdisciplinary Scientific International Conference for PhD Students and Assistants - QUAERE. Hradec Králové, Czech Republic, pp. 377-385.

7. HORTAI, F., 2016. An automated algorithm for generating neural networks for stock value prediction. Paper presented at: Proceedings of the 27th International Business Information Management Association Conference - Innovation Management and Education Excellence Vision 2020: From Regional Development Sustainability to Global Economic Growth. Milan, Italy, pp. 1069-1077.

8. KLIEŠTIK, T., J. VRBKA and Z. ROWLAND, 2018. Bankruptcy prediction in Visegrad group countries using multiple discriminant analysis. Equilibrium - Quarterly Journal of Economics and Economic Policy. 13(3), 569-593. doi: https://doi.org/10.24136/eq.2018.028

9. MOHAPATRA, A. et al., 2018. Applications of neural network-based methods on stock market prediction: Survey. International Journal of Engineering and Technology (UAE), 7(2), 71-76. doi: https://doi.org/10.14419/ijet.v7i2.6.10070

10. NIE, C., X. JIN, 2016. The interval slope method for long-term forecasting of stock price trends. Advances in Mathematical Physics. 2016(6), 1-7. doi: https://doi.org/10.1155/2016/8045656

11. PAI, P. F., C. S. LIN, 2005. A hybrid ARIMA and support vector machines model in stock price forecasting. Omega - International Journal of Management Science, 33(6), 497-505. doi: https://doi.org/10.1016/j.omega.2004.07.024

12. ROWLAND, Z., J. VRBKA, 2016. Using artificial neural networks for prediction of key indicators of a company in global world. Paper presented at: 18th International Scientific Conference Globalization and Its Socio-Economic Consequences. Rajecké Teplice, Slovakia, pp. 1896-1903.

13. SHEELAPRIYA, G., R. MURUGESAN, 2016. Stock price trend prediction using Bayesian regularised radial basis function network model. Spanish Journal of Finance and Accounting - Revista Española de Financiación y Contabilidad, 46(2), 189-211. doi: https://doi.org/10.1080/02102412.2016.1260859

14. STEHEL, V., M. VOCHOZKA, 2016. The analysis of the economical value added in transport. Nase More, 63(3), 185-188. doi: https://doi.org/10.17818/NM/2016/SI20

15. SVOBODA, M., 2016. Stochastic model of short-term prediction of stock prices and its profitability in the Czech stock market. E \& M: Ekonomie a Management, 19(2), 188-199. doi: http://dx.doi.org/10.15240/tul/001/2016-2-013

16. VOCHOZKA, M., T. KRULICKÝ, 2018. Analysis of enterprises in the manufacturing industry using artificial neural structures - Kohonen networks. Paper presented at: 18th International Scientific Conference Globalization and Its Socio-Economic Consequences. Rajecké Teplice, Slovakia, pp. 1927-1934.

17. VOCHOZKA, M., V. MACHOVÁ, 2018. Determination of value drivers for transport companies in the Czech Republic. Nase More, 65(4), 197-201. doi: http://dx.doi.org/10.17818/NM/2018/4SI.6

18. VOCHOZKA, M., A. MAROUŠKOVÁ and P. ŠULEŘ, 2018. Economic, environmental and moral acceptance of renewable energy: A case study - the agricultural biogas 
plant at Pěčín. Science and Engineering Ethics, 24(1), 299-305. doi: http://dx.doi.org/10.1007/s11948-017-9881-7

19. VOCHOZKA, M., 2017. Formation of complex company evaluation method through neural networks based on the example of construction companies' collection. $A D$ ALTA - Journal of Interdisciplinary Research, 7(2), 232-239.

20. VRBKA, J., Z. ROWLAND, 2017. Stock price development forecasting using neural networks. Paper presented at: SHS Web of Conferences: Innovative Economic Symposium 2017 - Strategic Partnership in International Trade. Beijing, China.

21. WANG, Y. C., T. N. NGUYEN, 2015. Forecasting Stock Prices for an Emerging Market: A Case of Vietnam. Paper presented at: Proceedings of the 2nd International Conference on Finance and Economics. Ho Chi Minh City, Vietnam, pp. 190-200.

22. WU, C. et al., 2015. Stock Price Forecasting: Hybrid Model of Artificial Intelligent Methods. Engineering Economics, 26(1), 40-48. doi: http://dx.doi.org/10.5755/j01.ee.26.1.3836

\section{Contact address of the authors:}

Mgr. Petr Šuleř, PhD., School of Valuation and Expertness, Institute of Technology and Business in České Budějovice, Okružní 517/10, České Budějovice 37001, Czech Republic, e-mail: petr.suler@cez.cz

Ing. Jakub Horák, Department of Economics, Faculty of Operation and Economics of Transport and Communications, University of Žilina, Univerzitná 8215/1, Žilina 01026, Slovakia, e-mail: horak@mail.vstecb.cz

Ing. Tomáš Krulický, BBA, Department of Economics, Faculty of Operation and Economics of Transport and Communications, University of Žilina, Univerzitná 8215/1, Žilina 01026, Slovakia, e-mail: krulicky@mail.vstecb.cz 